\title{
BMJ open Are neighbourhood food resources distributed inequitably by income and race in the USA? Epidemiological findings across the urban spectrum
}

\author{
Andrea S Richardson, ${ }^{1}$ Janne Boone-Heinonen, ${ }^{2}$ Barry M Popkin, ${ }^{1}$ \\ Penny Gordon-Larsen ${ }^{1}$
}

To cite: Richardson AS, Boone-Heinonen J, Popkin $\mathrm{BM}$, et al. Are neighbourhood food resources distributed inequitably by income and race in the USA?

Epidemiological findings across the urban spectrum. BMJ Open 2012;2:e000698. doi:10.1136/ bmjopen-2011-000698

- Prepublication history and additional appendices for this paper are available online. To view these files please visit the journal online (http://dx. doi.org/10.1136/

bmjopen-2011-000698)

Received 20 December 2011 Accepted 12 March 2012

This final article is available for use under the terms of the Creative Commons Attribution Non-Commercial 2.0 Licence; see http://bmjopen.bmj.com

${ }^{1}$ Department of Nutrition, University of North Carolina at Chapel Hill, Chapel Hill, North Carolina, USA

${ }^{2}$ Department of Public Health and Preventive Medicine, Oregon Health and Science University, Portland, Oregon, USA

Correspondence to Dr Penny Gordon-Larsen; pglarsen@unc.edu

\section{ABSTRACT}

Objective: Many recent policies focus on socioeconomic inequities in availability of healthy food stores and restaurants. Yet understanding of how socioeconomic inequities vary across neighbourhood racial composition and across the range from rural to urban settings is limited, largely due to lack of large, geographically and socio-demographically diverse study populations. Using a national sample, the authors examined differences in neighbourhood food resource availability according to neighbourhood-level poverty and racial/ethnic population in non-urban, low-density urban and high-density urban areas.

Design: Cross-sectional data from an observational cohort study representative of the US middle and high school-aged population in 1994 followed into young adulthood.

Participants: Using neighbourhood characteristics of participants in the National Longitudinal Study of Adolescent Health (Wave III, 2001-2002; $n=13995$ young adults aged 18-28 years representing 7588 US block groups), the authors examined associations between neighbourhood poverty and race/ethnicity with neighbourhood food resource availability in urbanicity-stratified multivariable linear regression.

\section{Primary and secondary outcome}

measures: Neighbourhood availability of grocery/ supermarkets, convenience stores and fast-food restaurants (measured as number of outlets per $100 \mathrm{~km}$ roadway).

Results: Neighbourhood race and income disparities were most pronounced in low-density urban areas, where high-poverty/high-minority areas had lower availability of grocery/supermarkets ( $\beta$ coefficient $(\beta)=-1.91,95 \% \mathrm{Cl}-2.73$ to -1.09$)$ and convenience stores ( $\beta=-2.38,95 \% \mathrm{Cl}-3.62$ to -1.14$)$ and greater availability of fast-food restaurants $(\beta=4.87$, $95 \% \mathrm{Cl} 2.26$ to 7.48 ) than low-poverty/low-minority areas. However, in high-density urban areas, highpoverty/low-minority neighbourhoods had comparatively greater availability of grocery/ supermarkets ( $\beta=8.05,95 \% \mathrm{Cl} 2.52$ to 13.57$)$, convenience stores ( $\beta=2.89,95 \% \mathrm{Cl} 0.64$ to 5.14 ) and fast-food restaurants ( $\beta=4.03,95 \% \mathrm{Cl} 1.97$ to 6.09 ), relative to low-poverty/low-minority areas.

\section{ARTICLE SUMMARY}

Article focus

- Using national data, we examined whether neighbourhood food resource availability exhibits joint race and socioeconomic inequities across levels of urbanicity.

Key messages

- Socio-demographic inequities in neighbourhood food resource availability were most pronounced in low-density urban (largely suburban) areas.

- In high-density urban areas, higher neighbourhood poverty was associated with greater availability of all food resources.

- Whereas policy has focused on dense urban settings, less urban areas might also benefit from policies addressing food access.

Strengths and limitations of this study

- While business records provide comparable data across the USA, these data may contain error and do not indicate availability of specific foods.

- National coverage enabled examination of the joint role of neighbourhood race and socioeconomic status across urban strata within a single study.

Conclusions: In addition to targeting disproportionate fast-food availability in disadvantaged dense urban areas, our findings suggest that policies should also target disparities in grocery/supermarket and fast-food restaurant availability in low-density areas.

\section{INTRODUCTION}

National, state and local policies increasingly focus on improving availability of healthy foods in disadvantaged neighbourhoods. Expectations that such policies will improve diets in low-income and race/ethnic minority populations stem from evidence that inequitable access to healthy foods may underlie differentials in diet quality, ${ }^{1-4}$ obesity $^{5}$ and 
related diseases by income and race/ethnicity (see reviews ${ }^{6-11}$ ). However, understanding the extent to which inequities in different types of food resources exist in different types of the US communities is limited by several factors.

First, research has focused on 'food deserts', generally defined as areas with limited access to affordable fresh foods from supermarkets (see reviews ${ }^{8-11}$ ). Subsequently, 'food swamps', ${ }^{12}{ }^{13}$ characterised as neighbourhoods with disproportionate access to convenient, energy-dense nutrient-poor foods sold by convenience stores and fast-food restaurants, emerged as important dimensions of the food environment. Thus, attention to a variety of food resources, such as supermarkets, convenience stores and fast-food restaurants, may be a more useful approach to examining neighbourhood food access. ${ }^{11} 1415$

Second, most existing food access initiatives target lowincome dense urban areas, yet inequities in access to healthy foods may be even more pronounced in suburban and rural areas due to greater dispersion of resources and car-dependent infrastructure. ${ }^{14}$ In addition, geographic distribution of food outlets relative to homes, transportation infrastructure and other resources differs across urbanicity, ${ }^{16}{ }^{17}$ perhaps due to differences in travel times to community resources ${ }^{18}$ and population density. Yet few studies examine how inequities in availability of food resources might vary by urbanicity, ${ }^{9}{ }^{19-21}$ and limited understanding relies on comparisons across small geographically specific study populations (eg, New Orleans compared with Texas colonias). Generalisable understanding requires large national study populations.

Third, allocation of food resources according to income has received the most focus, with some examination of race/ethnic differences. Consideration of neighbourhood socioeconomic status alone has not yielded consistent results, ${ }^{15}{ }^{22-24}$ which suggest that other neighbourhood characteristics underlie food resource allocation. Patterning by race/ethnicity may further compound patterning according to income and would underscore the importance of culturally sensitive policies. However, the joint role of neighbourhood race/ ethnic composition and neighbourhood income has received little attention. ${ }^{25}$

Using Geographic Information Systems-derived neighbourhood characteristics from a national sample of 13995 young adults across the USA provides variation and sufficient sample size to examine disparities in neighbourhood food resource availability according to income, race/ethnicity and urbanicity. We examined the joint role of neighbourhood race/ethnic composition and neighbourhood poverty across non-urban, lowdensity urban and high-density urban areas. Specifically, we tested whether individuals living in neighbourhoods composed of populations with high proportions of impoverished and minority residents had lower availability of grocery/supermarkets and greater availability of fast-food restaurants and convenience stores (compared with lower poverty areas with high proportion of nonHispanic white populations), and whether this distribution varied across less urban and more urban areas.

\section{METHODS}

\section{Study population and data sources}

Our study sample is derived from respondents aged 18-24 years who participated in Wave III (2001-2002) of the National Longitudinal Study of Adolescent Health (Add Health), a nationally representative prospective cohort study of adolescents of the US school-based population in grades 7-12 (11-22 years of age) in 1994-1995 who are followed into adulthood (Wave III). Subjects eligible for inclusion in the analytic sample included 14322 Wave III young adults with sample weights. The Add Health sample was collected under protocols approved by the Institutional Review Board at the University of North Carolina. The survey design and sampling frame have been discussed elsewhere. ${ }^{26} 27$

We used the Add Health Obesity and Neighbourhood Environment database (ONEdata), a Geographic Information System that includes time-varying community-level data geographically linked to respondent residential addresses geocoded with street-segment matches $(\mathrm{n}=13039)$, global positioning system measurements $(\mathrm{n}=1204)$ and ZIP/ZIP+4/ZIP+2 centroid match $(\mathrm{n}=685)$. Attributes of areas within 1, 3, 5 and $8.05 \mathrm{~km}$ of each respondent location (neighbourhood buffers) and block group, tract and county attributes from timematched US Census and other federal sources were merged with individual-level Add Health interview responses. $^{28}$ The number of census block groups $(\mathrm{n}=7588)$ represents $3.6 \%$ of 2000 US Census block groups.

Of 14322 Wave III respondents with sample weights, 327 (2.3\%) with missing food environment or the US census data were excluded, leaving an analytic sample of 13995 .

\section{Study variables}

Geographic Information Systems-derived neighbourhood data For our central analysis, we used residential locations linked to attributes of areas within $3 \mathrm{~km}$ straight-line distance (Euclidean buffer) and along the street network (street network buffer) surrounding each respondent's residential location in Wave III (2001). The $3 \mathrm{~km}$ buffer was designed to capture distances readily accessible by walking and driving to neighbourhood diet- and activityrelated resources. $^{2} 32930$ Comparative analyses were conducted with 1 and $8 \mathrm{~km}$ buffers. Neighbourhood food environment, socio-demographic and urban indicator data were merged with individual-level Add Health interview data.

\section{Food environment}

Food resource data were obtained from Dun and Bradstreet, a commercial data set of the US businesses. Food 
resources were classified according to 4- and 8-digit Standard Industrial Classification codes. Three categories of food resources were used: (1) fast-food restaurants, defined as fast-food chain and non-chain restaurants, excluding food stands and cafeterias; (2) grocery stores and supermarkets, defined as independent and chain grocery stores and supermarkets and (3) convenience stores, defined as variety and convenience stores and food stores attached to gasoline filling stations. Full details are described in online appendix A.

We characterised neighbourhood food resource availability as the count of each type of resource per roadway distance within a $3 \mathrm{~km}$ street network buffer, which represents availability to resources relative to the street network and potentially reflects routes of travel. ${ }^{31}$ While others have used measures such as the modified retail food environment index, ${ }^{32}$ which measures the availability of healthy relative to unhealthy food stores, ratio measures may obscure differential variation across food outlet types. Since this is a major focus of the current study, we use absolute measures of fast food, convenience stores and supermarkets and examine each resource type separately. In addition, by controlling for population density, we capture resources relative to what might be expected with respect to population distribution. Given the variation in classification of the food environment in the literature $\left(\right.$ see review ${ }^{33}$ ), we present findings across several different food environment measures (eg, count per population, distance to nearest outlet).

Given the importance of scaling resources by general urban development, we created measures of resources per $100 \mathrm{~km}$ of secondary/connecting and local neighbourhood and rural roads using street data obtained from StreetMap Pro (July 2003, V.5.2) data from Environmental Systems Research Institute (http://www.esri. com) in Redlands, California, USA. We selected the $3 \mathrm{~km}$ street network buffer after evaluating associations with resource availability and sensitivity of buffer size. We thus defined neighbourhood food resource availability as the number of outlets per $100 \mathrm{~km}$ of roadway within a $3 \mathrm{~km}$ network buffer to account for differences in food resource counts according to the amount of commercial activity in an area.

\section{Neighbourhood socio-demographics}

Census block groups were used to define neighbourhoods because smaller units are more likely to adhere to individually perceived neighbourhood boundaries ${ }^{34}$ and are more socio-demographically homogeneous. Using the federal definition of 'poverty area', ${ }^{35}{ }^{36}$ we dichotomised neighbourhood poverty into $>20 \%$ or $\leq 20 \%$ of population below the federal poverty level. We defined neighbourhood minority population as percentage of population of non-Hispanic white race/ethnicity and neighbourhood-level education as percentage of population $\geq 25$ years with college or greater education. While other studies have used a neighbourhood deprivation index to provide an 'empirical summary of total area- level variance explained by the census variables', ${ }^{37}$ we investigated neighbourhood race/ethnicity and income as separate constructs. We focus on these two specific characteristics to address the theoretical processes of resource placement in areas with greater purchasing power (income) and political leverage associated with the majority race. To evaluate potential interaction of neighbourhood poverty status with minority population, we created a categorical variable: (1) low poverty/low minority, (2) high poverty/low minority, (3) low poverty/medium minority, (4) high poverty/medium minority, (5) low poverty/high minority and (6) high poverty/high minority.

\section{Neighbourhood urbanicity}

Most studies characterise urbanicity based on population density. ${ }^{19}$ We improve on such traditional definitions by using the US Census-defined urbanised areas (UAs) that were used to classify residential locations as non-urban (outside UA) or urban (inside UA). Within urban areas, we used Fragstats ${ }^{38}$ software with the US Geologic Survey National Landcover Data to distinguish: (1) low-density ( $\leq 95 \%$ (75th percentile) developed land cover) and (2) high-density ( $>95 \%$ developed land cover) urban areas based on the area of developed land as a proportion of total area within $3 \mathrm{~km}$ after excluding water and ice. Our measure of developed land cover provides an indicator of urban development that is independent of population density and correctly classifies areas as within or outside the UA (receiver operating characteristic curve area $=0.937)$.

\section{Statistical analysis}

\section{Descriptive analysis}

Availability of food resources and socio-demographic characteristics were compared across non-urban, low-density urban and high-density urban strata. We examined urbanicity-specific tertiles of neighbourhood minority population (table 2) to address non-linear associations with food resource availability measures. All statistical analyses were weighted for national representation and corrected for complex survey design using Stata V.11.1 (Stata Corp).

\section{Multivariable regression analysis}

We fit multivariable linear regression models to predict food resource availability as a function of neighbourhood poverty and minority population where our constructed variable combining neighbourhood poverty (high and low) with levels of minority population (low, medium, high) explicitly estimates interactions relative to the theoretically most advantaged neighbourhoods (low poverty/low minority). Given that food resources and neighbourhood socio-demographics varied dramatically across urbanicity, comparability across sociodemographic and geographic subpopulations was difficult, even with our large sample size. Nonetheless, we have large samples of individuals and block groups 
Table 1 Urbanicity-specific* neighbourhood demographics, National Longitudinal Study of Adolescent Health, Wave III (2001-2002) $(n=13995)$

\begin{tabular}{|c|c|c|c|}
\hline & Non-urban & Low-density urban & High-density urban \\
\hline Count (census block groups) & 1530 & 4132 & 1935 \\
\hline Count (Add Health respondents) & 3779 & 6676 & 3549 \\
\hline$\%$ College educated or above, , mean (SD) & $16.6(0.8)$ & $25.5(1.1)$ & $22.2(1.8)$ \\
\hline \multicolumn{4}{|l|}{ Population density (persons $\left./ \mathrm{km}^{2}\right) \ddagger$, range } \\
\hline Low & $0.2-80.4$ & $15.4-981.3$ & $555.2-2651.2$ \\
\hline High & $80.7-2299.9$ & $981.4-26514.7$ & $2651.5-22952.4$ \\
\hline
\end{tabular}

across urbanicity strata, with adequate variation across neighbourhood socio-demographics (table 1). All models were weighted for national representation, corrected for clustering on our primary sampling unit (schools) and controlled for continuous neighbourhood-level education and population density dichotomised into urbanicity-specific quantiles. Given that schools and census block groups are not geographically nested, we did not use multilevel analysis. Furthermore, multilevel analysis of unbalanced sparse data within census block groups can result in biased estimates. ${ }^{39}$

To aid interpretation of the model results, we used the estimated model coefficients to predict food resource availability across levels of neighbourhood-level poverty and minority population within the low-density urban stratum, where the strongest disparities were observed.

\section{Comparative analyses}

In order to assess whether different neighbourhood buffer sizes were needed in urban versus non-urban areas, we compared and found similar patterns for the $1 \mathrm{~km}$ buffer in urban areas and the $8 \mathrm{~km}$ buffer in nonurban areas. In addition, we assessed alternate measures of food resource availability to compare our main measure findings with commonly used though conceptually different metrics: count per population ${ }^{2}$ and distance to nearest outlet. ${ }^{4} 14 \quad 40$ Specifically, we contrasted our roadway-scaled measure with: (1) density of food resources per 10000 population within $3 \mathrm{~km}$ Euclidean buffer and (2) minimum distance to the single nearest food resource within $8 \mathrm{~km}$ Euclidean buffer. We repeated identical multivariable regression models with alternate measures, except models with population-scaled measures did not control for population density. Results for food resources per $100 \mathrm{~km}$ of roadway within a $3 \mathrm{~km}$ network buffer are presented in text, while results for all other measures are shown in online appendices $\mathrm{B}$ and $\mathrm{C}$.

\section{RESULTS}

Neighbourhood availability of grocery/supermarkets, convenience stores and fast-food restaurants varied dramatically across non-urban, low-density urban and high-density urban areas, with greater availability in high-density urban areas (table 2).

In multivariable analysis, availability of grocery/ supermarkets and convenience stores for low-density urban residents did not differ according to neighbourhood poverty; rather, lower availability of food stores was observed with greater minority populations (table 3). Food stores were more equitably allocated in non-urban neighbourhoods. Interestingly, greater availability of food stores was often found in high-density urban areas with high proportions of low-income residents, but this relationship with neighbourhood income did not hold in neighbourhoods with high proportion of minority residents.

Fast-food availability was greater for residents in highpoverty neighbourhoods, with strongest associations in low- and high-density urban areas (table 3). Among those living in neighbourhoods with high poverty, greater minority population incurred additional inequities in food resource availability, particularly in low-density urban areas. In a notable exception, in highdensity urban, high-minority areas, fast food was less available in high-poverty neighbourhoods.

Figure 1 presents predicted food resource availability (based on the table 3 models) and more clearly illustrates the differential associations with poverty versus race/ethnicity in non-urban, low-density urban and high-density urban areas.

In general, estimated patterns of disparities were very similar between roadway-scaled, population density and distance measures (online appendices B and C).

\section{DISCUSSION}

We assessed inequities in grocery/supermarket, convenience store and fast-food restaurant availability by neighbourhood poverty and minority population in a large diverse national sample of residential neighbourhoods of young adults, representing 7588 census block groups (3.6\% of 2000 US Census block groups). Our findings suggest that inequities in neighbourhood food resource availability do exist, but not always where prior research suggests. In particular, racial and income disparities in availability of grocery/supermarkets were 
Table 2 Means (SD) of food resources* (count per $100 \mathrm{~km}$ secondary and local road within $3 \mathrm{~km}$ network buffer around each individual residence)†, National Longitudinal Study of Adolescent Health, Wave III (2001-2002) $(n=13995)$, by urbanicity $\neq$ and neighborhood povertyx $\{$ and minority populationx **

\begin{tabular}{|c|c|c|c|c|c|}
\hline \multicolumn{2}{|l|}{ Neighbourhood } & \multirow[b]{2}{*}{$\mathbf{N}$} & \multirow[b]{2}{*}{$\begin{array}{l}\text { Groceryl } \\
\text { supermarket }\end{array}$} & \multirow[b]{2}{*}{$\begin{array}{l}\text { Convenience } \\
\text { stores }\end{array}$} & \multirow[b]{2}{*}{ Fast food } \\
\hline $\begin{array}{l}\text { Per cent poverty§ } 9 \\
\text { within } 3 \mathrm{~km}\end{array}$ & $\begin{array}{l}\text { Per cent minority } \\
\text { population } \S{ }^{\star *} \text { within } 3 \mathrm{~km}\end{array}$ & & & & \\
\hline \multicolumn{6}{|l|}{ Non-urban } \\
\hline \multirow[t]{3}{*}{ Low } & Low & 545 & $0.22(0.08)$ & $0.91(0.42)$ & $2.48(0.47)$ \\
\hline & Medium & 954 & $0.14(0.03)$ & $0.34(0.07)$ & $2.04(0.23)$ \\
\hline & High & 1024 & $0.05(0.02)$ & $0.22(0.05)$ & $1.43(0.24)$ \\
\hline \multirow[t]{4}{*}{ High } & Low & 715 & $0.33(0.20)$ & $2.00(1.21)$ & $3.22(0.53)$ \\
\hline & Medium & 306 & $0.08(0.04)$ & $0.17(0.08)$ & $5.03(0.72)$ \\
\hline & High & 232 & $0.12(0.06)$ & $0.27(0.14)$ & $1.68(0.91)$ \\
\hline & Total & 3779 & $0.15(0.05)$ & $0.62(0.27)$ & $2.33(0.21)$ \\
\hline \multicolumn{6}{|l|}{ Low-density urban } \\
\hline \multirow[t]{3}{*}{ Low } & Low & 1320 & 3.47 (0.39) & $4.57(0.66)$ & $5.71(0.39)$ \\
\hline & Medium & 1757 & $1.90(0.17)$ & $2.77(0.19)$ & $5.30(0.21)$ \\
\hline & High & 2078 & $0.84(0.15)$ & $1.55(0.27)$ & $4.32(0.18)$ \\
\hline \multirow[t]{4}{*}{ High } & Low & 910 & $3.81(0.58)$ & $4.20(0.46)$ & $6.48(0.36)$ \\
\hline & Medium & 477 & $2.25(0.47)$ & $3.18(0.43)$ & $9.40(0.50)$ \\
\hline & High & 129 & $1.28(0.38)$ & $1.91(0.45)$ & $10.31(1.24)$ \\
\hline & Total & 6676 & $2.06(0.22)$ & $2.86(0.26)$ & $5.58(0.19)$ \\
\hline \multicolumn{6}{|l|}{ High-density urban } \\
\hline \multirow[t]{3}{*}{ Low } & Low & 767 & 8.21 (2.96) & $7.47(0.81)$ & $6.83(1.33)$ \\
\hline & Medium & 786 & $8.06(2.55)$ & $9.74(1.12)$ & 7.32 (1.17) \\
\hline & High & 870 & 7.19 (1.82) & $11.31(1.85)$ & $6.71(0.85)$ \\
\hline \multirow[t]{4}{*}{ High } & Low & 418 & $15.97(5.46)$ & $10.08(1.80)$ & $9.70(2.45)$ \\
\hline & Medium & 400 & 9.70 (4.22) & 9.69 (1.92) & 7.12 (2.13) \\
\hline & High & 307 & 7.09 (1.46) & $9.95(0.65)$ & 7.10 (1.20) \\
\hline & Total & 3549 & $8.72(2.31)$ & 7.24 (1.08) & $10.18(1.14)$ \\
\hline
\end{tabular}

*See online appendix A for Standard Industrial Classification codes for grocery/supermarkets, convenience stores and fast food.

tMeans (SD) corrected for clustering and weighted for representation.

$\ddagger$ Non-urban: distance to urbanised area (UA) $>0$; low-density urban: distance to $U A=0$ and \% developed land cover, excluding water and ice (land developed) $\leq 95 \%$; high-density urban: distance to $\cup A=0$ and $\%$ land developed $>95 \%$.

$\S$ Census block group.

\Greater than $20 \%$ of population below the federal poverty level.

${ }_{\star *}$ Per cent non-Hispanic white population. Non-urban (low: 0\%-74.7\%, medium: $74.8 \%-96.3 \%$, high: $96.4 \%-100 \%$ ), low-density urban (low: 0\%-70.7\%, medium: 70.8\%-90.5\%, high: $90.6 \%-100 \%$ ), high-density urban (low: 0\%-31\%, medium: $31.1 \%-63.7 \%$, high: $63.8 \%-100 \%$ ).

far more apparent in low-density urban areas than in high-density urban areas, where food deserts have been shown to exist. ${ }^{23}{ }^{41-43}$ In an unexpected finding, areas with high-poverty and high-minority population also have lower availability of convenience stores, which typically provide largely energy-dense nutrient-poor foods. ${ }^{44}$ Greater availability of fast food in areas with high-poverty rates and high-minority population was more consistent across non-urban, low-density urban and high-density urban areas.

Differences in availability of grocery/supermarkets, convenience stores and fast-food restaurants were most consistent in low-density urban areas, which include the largest proportion of our sample and theoretically captures suburban America. In the USA, we also note that the distribution of poverty has shifted away from the dense inner cities. Data from the 2010 census suggest that counter to the assumption of 'White Flight' out of inner cities, racial minorities, foreign-born and lowincome people were more likely to live in metropolitan suburbs in 2010 than the cities they lived in during $2008 .{ }^{46}$ Thus, the income and race/ethnic disparities in neighbourhood food resource availability observed in low-density urban areas in our 2001 data may become much more important as poor and minority populations increasingly reside in suburban neighbourhoods. Our findings suggest that in addition to increasing grocery store availability and limiting fast-food availability in disadvantaged dense urban areas, rural and suburban areas should be targeted for food environment improvements. While this idea has been suggested by a series of studies in rural Texas, ${ }^{20}$ our national study further supports more focus on rural and suburban food environments.

Relationships between food resource availability, neighbourhood poverty and minority population were notably distinct in high-density urban areas. It is possible that fewer significant findings in high-density urban areas might reflect lower statistical power due to smaller sample size (1935 high-density urban vs 4132 low-density urban block groups) or greater variability in high-density urban relative to other areas. Yet, the pattern of findings suggests variation across the spectrum of urbanicity. First, our finding of greater availability of grocery stores 


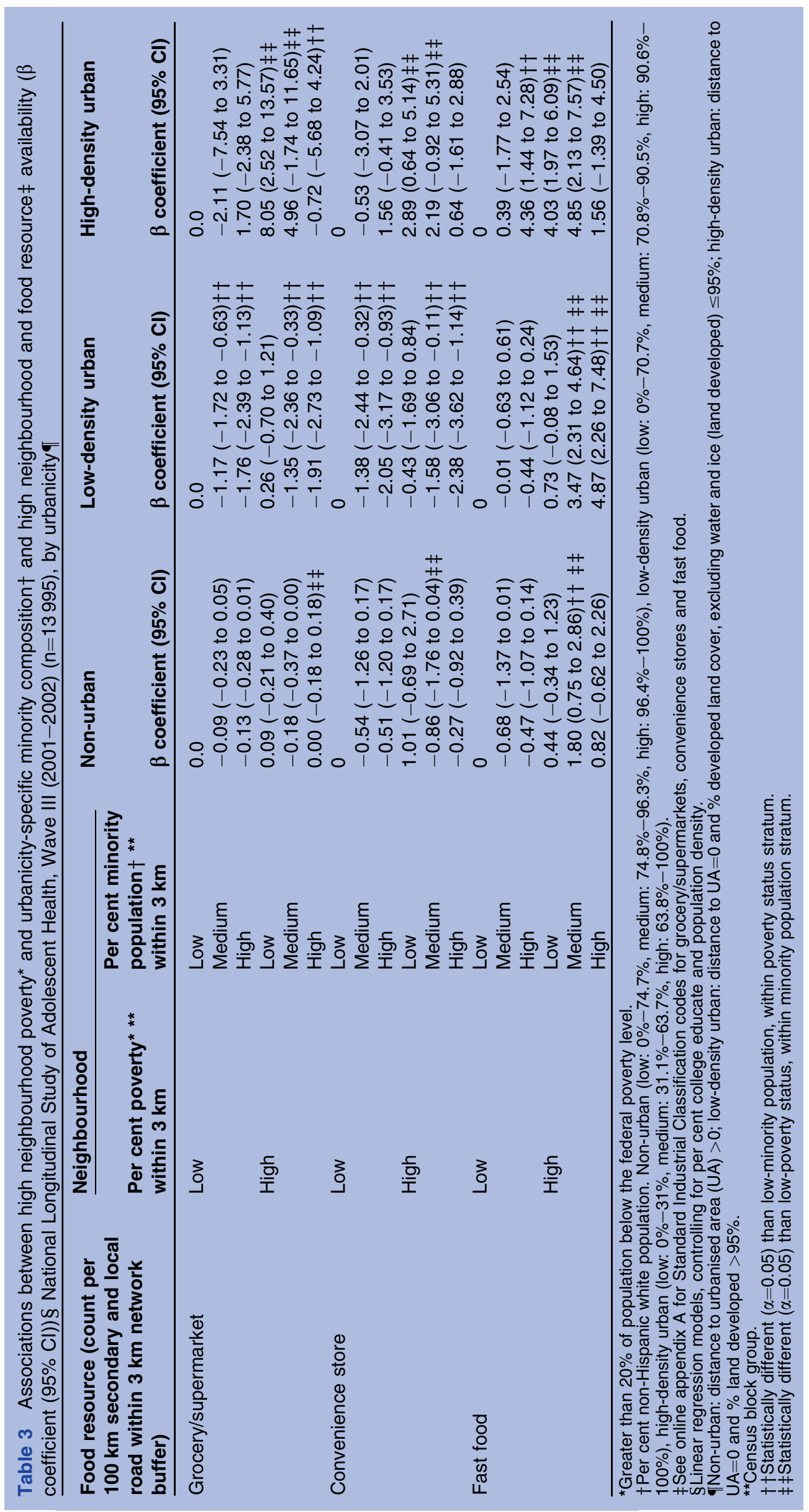



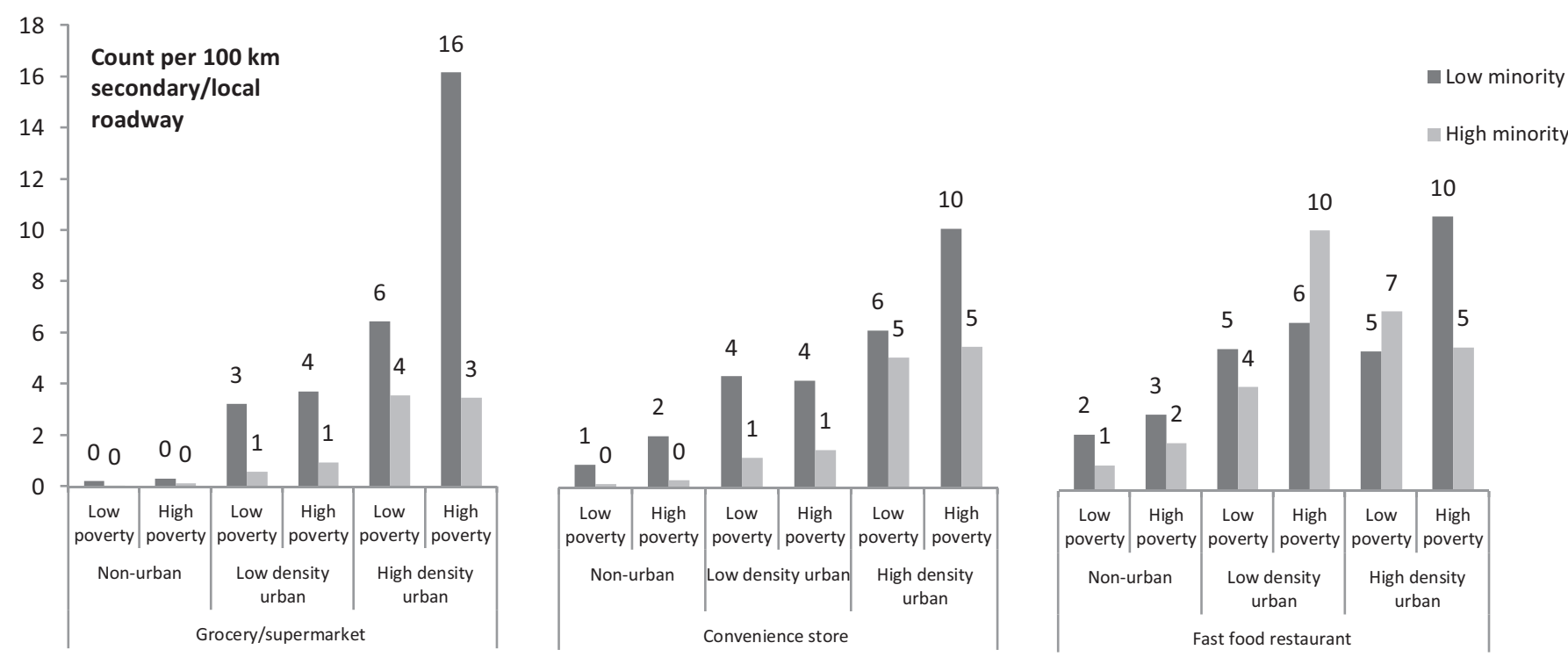

Figure 1 Predicted neighbourhood food resource availability (count per 10000 population) for various neighbourhood poverty* and minority population† levelsł. ${ }^{*}$ Greater than $20 \%$ of population below the federal poverty level. †Per cent non-Hispanic White population. Non-urban (low: 0\%-74.7\%, medium: $74.8 \%-96.3 \%$, high: $96.4 \%-100 \%$ ), low-density urban (low: 0\%-70.7\%, medium: $70.8 \%-90.5 \%$, high: $90.6 \%-100 \%$ ), high-density urban (low: $0 \%-31 \%$, medium: $31.1 \%-63.7 \%$, high: $63.8 \%-10 \%$ ). ¥National Longitudinal Study of Adolescent Health Wave III (young adulthood: 2001-2002), corrected for clustering and weighted for representation. Estimated from urbanicity-stratified regression modelling food resource availability (within $3 \mathrm{~km}$ network buffer) as a function of neighbourhood poverty status ( $>20 \%$ population below federal poverty level compared with $\leq 20 \%$ of population below federal poverty level) and percent non-Hispanic White population. Non-urban (Low:0-74.7\%, High: 96.4-100\%), Low density urban (Low: 0-70.7\%, High: 90.6-100\%) High density urban (Low: 0-31\%, High: 63.8-10\%) For simplicity, predictions for medium neighbourhood minority population are not reported.

and convenience stores in high- versus low-poverty areas, but only in areas with predominately white populations, suggests the presence of complex economic and social drivers in where food stores choose to locate. Second, fast-food availability was generally greater in highpoverty, high-minority areas, but this was not true in high-minority, high-density urban areas. This finding is consistent with prior evidence ${ }^{114}$ that perceived or real racial tensions or safety concerns may also influence opening and closure of food establishments.

Findings using our main roadway-scaled measures and population density measures were nearly identical as they likely capture resources scaled by commercialisation and development indicated by population and roadways. Slight inconsistencies in results for the minimum distance measures may reflect greater variation that results from using a single data point (nearest outlet) to characterise availability compared with incorporating data from multiple food resources within an area. Minimum distance measures also do not account for differential distribution of food resources according to the population and development density.

\section{Strengths and limitations}

This study did not look at extreme poverty nor consider a large array of other factors linked with urbanicity. It is possible that disparities in food resources in dense urban areas may be evident only under extreme neighbourhood poverty that we did not examine in our analysis. More refined analyses of dynamic effects among social and economic environments and food resources are beyond the scope of the present analysis, though they certainly warrant further attention. Moreover, other factors such as crime, ${ }^{47}$ aesthetics ${ }^{47}$ travel time ${ }^{48}$ or proximity to other resources ${ }^{47}$ could also relate to actual or perceived access to food resources.

The benefit of business record data, which provides comparative national food resource data, must be balanced with their limitations. Business record data contain error, which can bias results either towards the null if misclassification is non-differential or away from the null in the case of differential misclassification. It is also possible that the accuracy of business records varies by area socio-demographics and/or urbanicity. ${ }^{49-53}$ Neighbourhood audits (street-by-street data collection by researchers) better capture broader dimensions of food access, such as food prices or cultural preferences, but they are not feasible for large national samples across thousands of census blocks groups. These intense audits are generally performed in smaller geographic areas and thus preclude broad comparisons across neighbourhood type and sociodemographics. We were unable to ascertain food sold at each establishment and relied on generalisations regarding healthy (grocery/supermarket) versus unhealthy (convenience store, fast-food restaurant) types of establishments.

Although supercentres have recently gained a significant share of the food retailing market, during the contemporaneous study period, supercentres held only 
a minority proportion of the household purchases compared with grocery stores and supermarkets. ${ }^{54}$ Furthermore, access to supercentres often requires driving outside the residential neighbourhoods, given their size and placement. For these reasons, supercentres were not addressed.

Furthermore, due to lower participation of illegal immigrants in the census, the US census data may underestimate neighbourhood minority population and poverty. Our $3 \mathrm{~km}$ network residential neighbourhood buffer may not accurately reflect food purchasing areas for different urban settings and socio-demographic subgroups; this is a topic worthy for future study. In addition, this is a cross-sectional study and thus does not capture changes in food environments over time.

Despite these limitations, our study is an essential step in understanding the allocation of theoretically healthy and less healthy food resources across social and geographic space over the entire USA, and our findings can inform measurement and design in future individuallevel and longitudinal studies. Our study benefits from the variation in neighbourhoods of a large population that enables comparisons across multiple socio-demographic and urban strata within a single study. Furthermore, our study capitalises upon national data with roadway-scaled measures of neighbourhood food resource availability within $3 \mathrm{~km}$ residential network buffers for each observation. In addition, we used detailed measures of urbanicity derived both from the US census and land cover data allowing a more refined urban/rural classification than the traditional urban/rural dichotomy. In sum, our study benefits from several innovations and depth of coverage that has been heretofore unaddressed in a large geographically diverse study.

\section{Policy implications}

Many state and national efforts focus on providing healthy eating options for poor inner-city neighbourhoods, many with high-minority populations. Strategies include providing produce carts in low-income neighbourhoods in New York City, ${ }^{55}$ directly or indirectly subsidising supermarkets, ${ }^{56-59}$ banning fast-food restaurant construction in selected urban areas, ${ }^{60}$ as well as legislation considered at the national level. ${ }^{61}$ Our results suggest that less urban areas might benefit from similar policies.

\section{Conclusions}

Our findings suggest that common assumptions regarding income and race/ethnic subpopulation disparities in food resources may not be universally true across the spectrum of urbanicity. We observed an association between greater neighbourhood poverty and minority population with greater availability of fast-food restaurants in urban areas. Conversely, disparities in grocery/supermarkets were primarily observed in low-density urban areas. Our findings suggest that poverty and race may play distinct roles in how food resources are allocated and that underlying social complexities should be further explored in dense urban, suburban and rural areas.

Acknowledgements The authors thank Brian Frizzelle, Marc Peterson, Chris Mankoff, James D. Stewart, Phil Bardsley and Diane Kaczor of the University of North Carolina, Carolina Population Center (CPC) and the CPC Spatial Analysis Unit for creation of the environmental variables. The authors also thank Ms Frances Dancy for her helpful administrative assistance. There were no potential or real conflicts of financial or personal interest with the financial sponsors of the scientific project.

Contributors The authors have each made (1) substantial contributions to conception and design, acquisition of data or analysis and interpretation of data; (2) drafting the article or revising it critically for important intellectual content and (3) final approval of the version to be published.

Funding This work was funded by National Institutes of Health grant R01HD057194, R01HL104580, R01HD041375, R01HD39183 and

R01HLI04580, a cooperative agreement with the Centers for Disease Control and Prevention (CDC SIP No. 5-00). The authors are also grateful to R24 HD050924 from the Eunice Kennedy Shriver National Institute of Child Health and Human Development (NICHD) for broad support of the authors, although no funding was provided by this grant. Analysis and manuscript preparation was supported by the Interdisciplinary Obesity Training postdoctoral fellowship (T32MH075854-04).

\section{Competing interests None.}

Ethics approval Ethics approval was provided by the Institutional Review Board at the University of North Carolina.

Provenance and peer review Not commissioned; externally peer reviewed.

Data sharing statement This research uses data from Add Health, a programme project designed by J Richard Udry, Peter S Bearman and Kathleen Mullan Harris and funded by a grant P01-HD31921 from the Eunice Kennedy Shriver National Institute of Child Health and Human Development, with cooperative funding from 17 other agencies. Special acknowledgement is due Ronald R Rindfuss and Barbara Entwisle for assistance in the original design. Persons interested in obtaining data files from Add Health should contact Add Health, CPC, 123 W. Franklin Street, Chapel Hill, NC 27516-2524 (addhealth@unc.edu). No direct support was received from grant P01-HD31921 for this analysis.

\section{REFERENCES}

1. de Vet E, de Ridder DT, de Wit JB. Environmental correlates of physical activity and dietary behaviours among young people: a systematic review of reviews. Obes Rev 2011;12:e130-42.

2. Boone-Heinonen J, Gordon-Larsen P, Kiefe Cl, et al. Fast food restaurants and food stores: longitudinal associations with diet in young to middle-aged adults: the CARDIA study. Arch Intern Med 2011;171:1162-70.

3. Richardson AS, Boone-Heinonen J, Popkin BM, et al. Neighborhood fast food restaurants and fast food consumption: a national study. BMC Public Health 2011;11:543.

4. Timperio A, Ball K, Roberts R, et al. Children's fruit and vegetable intake: associations with the neighbourhood food environment. Prev Med 2008;46:331-5.

5. Zick CD, Smith KR, Fan JX, et al. Running to the store? The relationship between neighborhood environments and the risk of obesity. Soc Sci Med 2009;69:1493-500.

6. Giskes K, van Lenthe F, Avendano-Pabon M, et al. A systematic review of environmental factors and obesogenic dietary intakes among adults: are we getting closer to understanding obesogenic environments? Obes Rev 2011;12:e95-106.

7. Fleischhacker SE, Evenson KR, Rodriguez DA, et al. A systematic review of fast food access studies. Obes Rev 2011;12:e460-71.

8. Beaulac J, Kristjansson E, Cummins S. A systematic review of food deserts, 1966-2007. Prev Chronic Dis 2009;6:A105.

9. Institute of Medicine and National Research Council. Workshop on the Public Health Effects of Food Deserts: Workshop Summary. Washington DC: National Academy, 2009.

10. Larson NI, Story MT, Nelson MC. Neighborhood environments: disparities in access to healthy foods in the U.S. Am J Prev Med 2009;36:74-81.

11. Walker RE, Keane CR, Burke JG. Disparities and access to healthy food in the United States: a review of food deserts literature. Health Place 2010;16:876-84. 
12. Rose D, Bodor NJ, Swalm CM, et al. Deserts in New Orleans? Illustrations of urban food access and implications for policy. Ann Arbor, Ml: University of Michigan National Poverty Center/USDA Economic Research Service Research "Understanding the Economic Concepts and Characteristics of Food Access". 2009.

13. Sturm R. Affordability and obesity: issues in the multifunctionality of agricultural/food systems. J Hunger Environ Nutr 2009;4:454-65.

14. USDA. Access to Affordable and Nutritious Food: Measuring and Understanding Food Deserts and Their Consequences: Economic Research Service. Washington DC: Economic Research Service, 2009.

15. Pearce J, Blakely $\mathrm{T}$, Witten $\mathrm{K}$, et al. Neighborhood deprivation and access to fast-food retailing: a national study. Am J Prev Med 2007;32:375-82.

16. Langellier BA. The food environment and student weight status, Los Angeles county, 2008-2009. Prev Chronic Dis 2012;9:E61.

17. Ahern M, Brown C, Dukas S. A national study of the association between food environments and county-level health outcomes. $J$ Rural Health 2011;27:367-79.

18. Pearce J, Witten $\mathrm{K}$, Hiscock $\mathrm{R}$, et al. Regional and urban - rural variations in the association of neighbourhood deprivation with community resource access: a national study. Environ Plan $A$ 2008:40(10):2469-89.

19. Sharkey JR, Horel S. Neighborhood socioeconomic deprivation and minority composition are associated with better potential spatial access to the ground-truthed food environment in a large rural area. J Nutr 2008;138:620-7.

20. Sharkey JR, Horel S, Han D, et al. Association between neighborhood need and spatial access to food stores and fast food restaurants in neighborhoods of colonias. Int J Health Geogr 2009;8:9

21. Smith DM, Cummins S, Taylor M, et al. Neighbourhood food environment and area deprivation: spatial accessibility to grocery stores selling fresh fruit and vegetables in urban and rural settings. Int J Epidemiol 2010;39:277-84.

22. Macdonald L, Ellaway A, Macintyre S. The food retail environment and area deprivation in Glasgow City, UK. Int J Behav Nutr Phys Act 2009;6:52.

23. Wang MC, Kim S, Gonzalez AA, et al. Socioeconomic and foodrelated physical characteristics of the neighbourhood environment are associated with body mass index. J Epidemiol Community Health 2007;61:491-8.

24. Wilson K, Eyles J, Ellaway A, et al. Health status and health behaviours in neighbourhoods: a comparison of Glasgow, Scotland and Hamilton, Canada. Health Place 2010;16:331-8.

25. Baker EA, Schootman M, Barnidge $\mathrm{E}$, et al. The role of race and poverty in access to foods that enable individuals to adhere to dietary guidelines. Prev Chronic Dis 2006;3:A76.

26. Miller WC, Ford CA, Morris M, et al. Prevalence of chlamydial and gonococcal infections among young adults in the United States. JAMA 2004;291:2229-36.

27. Resnick MD, Bearman PS, Blum RW, et al. Protecting adolescents from harm. Findings from the national longitudinal study on adolescent health. JAMA 1997;278:823-32.

28. Boone-Heinonen J, Evenson KR, Song Y, et al. Built and socioeconomic environments: patterning and associations with physical activity in U.S. adolescents. Int J Behav Nutr Phys Act 2010;7:45.

29. Zenk SN, Schulz AJ, Matthews SA, et al. Activity space environment and dietary and physical activity behaviors: a pilot study. Health Place 2011;17:1150-61.

30. Hillier A, Cannuscio C, Karpyn A, et al. How far do low-income parents travel to shop for food? Empirical evidence from two urban neighborhoods. Urban Geogr 2011;32:712-29.

31. Oliver LN, Schuurman N, Hall AW. Comparing circular and network buffers to examine the influence of land use on walking for leisure and errands. Int J Health Geogr 2007;6:41.

32. CDC. Children's Food Environment State Indicator Report: Centers for Disease Control and Prevention. Atlanta, GA: Centers for Disease Control and Prevention, 2011.

33. Feng J, Glass TA, Curriero FC, et al. The built environment and obesity: a systematic review of the epidemiologic evidence. Health Place 2010;16:175-90.

34. Boone-Heinonen J, Popkin BM, Song Y, et al. What neighborhood area captures built environment features related to adolescent physical activity? Health \& Place 2010;16:1280-6.

35. Subramanian SV, Chen JT, Rehkopf DH, et al. Racial disparities in context: a multilevel analysis of neighborhood variations in poverty and excess mortality among black populations in Massachusetts. Am $J$ Public Health 2005;95:260-5.

36. U.S. Census Bureau. Statistical Brief- Poverty Areas. 1995. http:// www.census.gov/population/socdemo/statbriefs/povarea.html (accessed 19 Jan 2010)
37. Messer LC, Laraia BA, Kaufman JS, et al. The development of a standardized neighborhood deprivation index. Urban Health 2006;83:1041-62.

38. McGarigal K, Cushman SA, Neel MC, et al. FRAGSTATS: Spatial Pattern Analysis Program for Categorical Maps. Amherst: Computer software program produced by the authors at the University of Massachusetts, 2002. http://www.umass.edu/landeco/research/ fragstats/fragstats.html

39. Clarke P. When can group level clustering be ignored? Multilevel models versus single-level models with sparse data. $J$ Epidemiol Community Health 2008;62:752-8.

40. Jago R, Baranowski T, Baranowski JC, et al. Distance to food stores \& adolescent male fruit and vegetable consumption: mediation effects. Int J Behav Nutr Phys Act 2007;4:35.

41. Morland K, Filomena S. Disparities in the availability of fruits and vegetables between racially segregated urban neighbourhoods. Public Health Nutr 2007:10:1481-9.

42. Block JP, Scribner RA, DeSalvo KB. Fast food, race/ethnicity, and income: a geographic analysis. Am J Prev Med 2004;27:211-17.

43. Zenk SN, Powell LM. US secondary schools and food outlets. Health Place 2008;14:336-46.

44. Borradaile KE, Sherman S, Vander Veur SS, et al. Snacking in children: the role of urban corner stores. Pediatrics 2009; 124:1293-8.

45. Lucan SC, Karpyn A, Sherman S. Storing empty calories and chronic disease risk: snack-food products, nutritive content, and manufacturers in Philadelphia corner stores. J Urban Health 2010;87:394-409.

46. The Brookings Institution Metropolitan Policy Program. State of Metropolitan America: on the Front Lines of Demographic

Transformation. Washington DC: The Brookings Institution, 2010.

47. Lovasi GS, Hutson MA, Guerra M, et al. Built environments and obesity in disadvantaged populations. Epidemiol Rev 2009;31:7-20.

48. Raja S, Ma C, Yadav P. Beyond food deserts: measuring and mapping racial disparities in neighborhood food environments. $J$ Plann Educ Res 2008;27:469-82.

49. Liese AD, Colabianchi N, Lamichhane AP, et al. Validation of 3 food outlet databases: completeness and geospatial accuracy in rural and urban food environments. Am J Epidemiol 2010;172:1324-33.

50. Hoehner CM, Schootman M. Concordance of commercial data sources for neighborhood-effects studies. J Urban Health 2010;87:713-25.

51. Longacre MR, Primack BA, Owens PM, et al. Public directory data sources do not accurately characterize the food environment in two predominantly rural states. J Am Diet Assoc 2011;111:577-82.

52. Powell LM, Han E, Zenk SN, et al. Field validation of secondary commercial data sources on the retail food outlet environment in the U.S. Health Place 2011;17:1122-31.

53. Cummins S, Macintyre S. Are secondary data sources on the neighbourhood food environment accurate? Case-study in Glasgow, UK. Prev Med 2009;49:527-8.

54. A.C. Nielsen Company. FMI/ACNielsen Study: Winning Strategies for Your Most Important Shoppers. New York, NY: A.C. Nielsen Company, 2005

55. NYC Department of Health and Mental Hygiene. NYC Green Cart. New York City, 2008. http://www.nyc.gov/html/doh/html/cdp/ cdp_pan_green_carts.shtml (accessed Apr 3, 2012).

56. The Reinvestment Fund. Commercial Real Estate: Supermarkets. New Jersey, 2010. http://www.trfund.com/financing/Healthy_food/ Healthy Food Retail.html (accessed Apr 3, 2012).

57. Lombino D, Patterson J. New York City Industrial Development Agency Approves Incentives for First Two Supermarkets Under the Fresh Program. New York City, 2010. http://newyork.realestaterama. com/2010/02/10/new-york-city-industrial-development-agencyapproves-incentives-for-first-two-supermarkets-under-the-freshprogram-ID0996.html (accessed Apr 3, 2012).

58. Stephens C. State of Louisiana Approves $\$ 7$ Million for Fresh Food Initiative in New Orleans. 2009. http://www.Ira.louisiana.gov/index. $\mathrm{cfm}$ ?md?newsroom\&tmp $=$ detail\&articlelD $=582 \& s s i d=0($ accessed Apr 3, 2012).

59. The Food Trust. Pennsylvania Fresh Food Financing Initiative. Philadelphia, 2004. http://www.thefoodtrust.org/php/programs/fffi.php (accessed Apr 3, 2012).

60. Los Angeles City Clerk. FAST FOOD RESTAURANTS / INTERIM CONTROL ORDINANCE / WEST-ADAMS-BALDWIN HILLSLEIMERT, SOUTH AND SOUTHEAST LOS ANGELES. LOS Angeles: LA City Clerk, 2008. http://cityplanning.lacity.org/Code Studies/Misc/FastFoodlnterim.pdf (accessed Apr 3, 2012).

61. Letsmove.gov. Accessing Healthy \& Affordable Food. Washington DC, 2010. http://letsmove.gov/accessing/index.html (accessed 4 May 2010). 